Article

\title{
The Use of Non-destructive Methods to Detect Non-metallic Reinforcement in Concrete and Masonry
}

\author{
Łukasz Drobiec ${ }^{1 *}$, Radosław Jasiński ${ }^{2}$ and Wojciech Mazur ${ }^{3}$ \\ 1 Silesian University of Technology, Department of Building Structures; ul. Akademicka 5, 44-100 Gliwice, \\ Poland, lukasz.drobiec@polsl.pl \\ 2 Silesian University of Technology, Department of Building Structures; ul. Akademicka 5, 44-100 Gliwice, \\ Poland, radoslaw.jasinski@polsl.pl \\ 3 Silesian University of Technology, Department of Building Structures; ul. Akademicka 5, 44-100 Gliwice, \\ Poland, wojciech.mazur@polsl.pl \\ * Correspondence: lukasz.drobiec@polsl.pl, Phone No. +48 32 237-11-27
}

\begin{abstract}
An increasing use of non-metallic reinforcement is problematic as it has to be detected at the stage of accepting construction works, or later when expert opinions are prepared for the building. In contrast to metallic reinforcement, location of this type of reinforcement is difficult using non-destructive techniques. Small diameters of rebars and their location in a tested element were troublesome. This article describes an attempt to locate non-metallic reinforcement in a concrete element and the masonry. Tests were performed using an ultrasonic tomograph and GPR with a broad range of frequencies.
\end{abstract}

Keywords: Rebar location, FRP reinforcement, NDT Methods, GPR Testing, Ultrasonic Testing, Electromagnetic Testing

\section{Introduction}

Non-metallic (FRP) reinforcement was launched on the market over 20 years ago as an alternative to conventional bars and steel meshes for reinforcing concrete and the masonry. As there were many doubts about characteristics of this material, no unambiguous qualitative standards for its production, resistance to high temperatures, and until recently no design procedures, construction engineers were initially quite sceptic about this type of reinforcement. Advantages of this reinforcement are durability, and especially resistance to corrosion, high tensile strength, and very low specific gravity. These make the non-metallic reinforcement more and more popular.

Non-metallic reinforcement in concrete structures is usually applied in wall and slab elements, which do not require any bent bars and reinforcement anchorage can be performed easily [1, 2]. Moreover, research works are conducted on the reinforcement for beam elements without stirrups [3] and preparation of hybrid beams with steel and non-metallic reinforcement [4]. There are no contraindications to employ reinforcement in elements exposed to puncturing and twisting [3]. Smaller plastic deformations reduce the possibility for using non-metallic reinforcement in structures, for which redistribution of bending moments (slabs and continuous beams) is permitted.

In masonry structures, the non-metallic reinforcement is applied in places of concentrated stresses, such as the zone below the window [5, 6], in places of concentrated loads [7], in zones connecting perpendicular walls [8]. The reinforcement can be sometimes used to reduce the risk of crack formation or increased resistance $[9,10]$.

As the non-metallic reinforcement is more common in reinforced concrete and masonry structures, there are problems regarding their diagnosing. Detecting non-metallic rebars of low diameters at the stage of works acceptance, or performing expert works is difficult and often requires the professional diagnostic equipment. This article describes an attempt to localise 
non-metallic reinforcement in concrete and masonry. Prepared tests elements were subjected to non-destructive testing with the GPR equipment and the ultrasonic tomograph.

\section{Potential of non-destructive tests for locating the reinforcement}

Nowadays, non-destructive tests on reinforcement location in the structure are carried out using the radar, electromagnetic, radiologic (radiographic), ultrasonic, and thermography techniques $[11,12,13,14,15]$. The radiologic technique was commonly applied in the 1960's and 70's since it produced the best results. This technique is based on $X, \gamma$ or other hard radiation and its recording which follows radiation emitted to the tested facility. During tests on structures, recording was made using special photographic films sensitive to ionising radiation. Currently, radiographic techniques are rarely used because of the long testing time and time-consuming elaboration of results.

The ultrasonic technique is an acoustic technique based on analysing relations between the velocity of elastic waves with a frequency of $20 \div 500 \mathrm{kHz}$, propagating in a permanent structure and its properties. These methods are mainly employed to determine the strength of concrete and masonry, detect voids and discontinuities of the structure, and test the depth of cracks. The use of ultrasonic technique for locating the reinforcement is justified by varying velocity of an acoustic wave in concrete or the masonry, and in the reinforcement. The velocity of an ultrasonic wave in concrete is $3500 \div 4500 \mathrm{~m} / \mathrm{s}$, whereas the wave velocity along the simple uncemented reinforcement in steel found in engineering constructions is $5850 \div 5890 \mathrm{~m} / \mathrm{s}$. Until recently, low precision of this method caused that it was not suitable for locating the reinforcement. Modern devices for ultrasonic thermography increase the measured accuracy on the basis of the elastic wave with a multi-head antenna equipped with independent ultrasonic transducers. So, tests on locating the reinforcement are performed with this method $[16,17,18]$.

Infrared thermography consists in recording, processing and visualising the invisible IR emitted by the body. Infrared thermography usually uses the medium IR band with a wavelength of 0.9-14 $\mu \mathrm{m}$. A thermal image (thermogram) is the result of tests capturing temperature distribution over the area of the tested body. Non-destructive tests using infrared thermography can be classified into procedures of passive and active tests $[14,19]$. Passive thermography analyses heat emitted by material without any additional thermal simulation, whereas active thermography is based on thermal analyses of the material response after its exposure to heat. Thermography can be used to localise the reinforcement as concrete and steel have different thermal properties. And thermographic techniques give very promising results $[19,20]$. However, they are now at the phase of laboratory tests. The market does not offer any thermographic devices for testing the reinforcement.

Nowadays, the most popular non-destructive techniques for detecting the reinforcement are electromagnetic and radar techniques. Electromagnetic methods for locating the reinforcement in reinforced concrete elements usually involve the analysis of changes in the magnetic field near rebars [11, 14]. But this method is only suitable for detecting metallic reinforcement. GPR (Ground-Penetrating Radar) method is based on emitting electromagnetic waves in the ultrashort and short frequencies of radio waves and recording waves reflected from layers characterised by varying dielectric properties. James Clerk Maxwell developed fundamentals for electromagnetic waves theory in 1864. This theory was not used in practice for a very long time. GPR techniques for reinforced concrete structure were rarely used until the 1980's [12, 14, 21, 22]. At that time, both the measuring technique and methods of result interpretation were improved. Nowadays, there are many measuring systems with varying measurement ranges and different levels of interpreting results. Thus, this method is often used to localise the reinforcement [23, 24, 25]. The assumed measurement range of $1.0 \div 3.0 \mathrm{GHz}$ offered by devices available on the market limits the method accuracy. Lower frequencies make tests possible at greater depths, and higher ones can detect small bodies localised near a tested edge. Density and porosity of tested concrete also affect the results. Due to wave suppression, tests are usually performed on concrete with the standard density within the range of $2400-2700 \mathrm{~kg} / \mathrm{m}^{3}$, less commonly on light concrete with density from 350 to $1500 \mathrm{~kg} / \mathrm{m}^{3}$. 
Non-metallic reinforcement applied in reinforced concrete structures, is usually characterised with diameters greater than or equal to $5 \mathrm{~mm}$, whereas masonry structures (with standard or thin joints) usually have meshes with weave and the diameter up to $1 \mathrm{~mm}$, which are more difficult to localise. Difficulties in detecting reinforcement in masonry structures are also caused by its location. Contrary to reinforced concrete structures, the reinforcement is horizontal, that is, in a perpendicular direction to the tested area because it is usually laid in head joints of the masonry, often in thin joints.

This article describes an attempt to localise non-metallic reinforcement in the concrete element and the masonry wall. The analysis described above, was used for selecting a testing method, that is, the ultrasonic tomograph with 24 exponential transducers and the GPR device with antennae having a wide range of frequencies $0.2-4.0 \mathrm{GHz}$.

\section{Tested specimens}

Tests were conducted on a reinforced concrete slab and two specimens built from the masonry with reinforcement laid in support joints. The slab was made from concrete class C20/25 (density of $2500 \mathrm{~kg} / \mathrm{m}^{3}$ ) and the bar mesh from fibreglass rebars with a diameter of $5.1 \mathrm{~mm}$ at a spacing of $10 \mathrm{~cm}$. The slab thickness was $12 \mathrm{~cm}$, and the mesh was laid together with a concrete cover of $25 \mathrm{~mm}$. The slab is illustrated in Fig. 1, and the reinforcement is shown in Fig. 2. The reinforcement was made from main wires and braided wires laid in a perpendicular direction to main wires. Main wires prepared traditionally in the pultrusion process, and perpendicular wires were made from braided glass fibres by resin hardening. Tensile strength of main wires was $1200 \mathrm{~N} / \mathrm{mm}^{2}$, and that of weaves was $600 \mathrm{~N} / \mathrm{mm}^{2}$. Young's modulus was $50000 \mathrm{~N} / \mathrm{mm}^{2}$, and the density was $1250 \mathrm{~kg} / \mathrm{m}^{3}$.
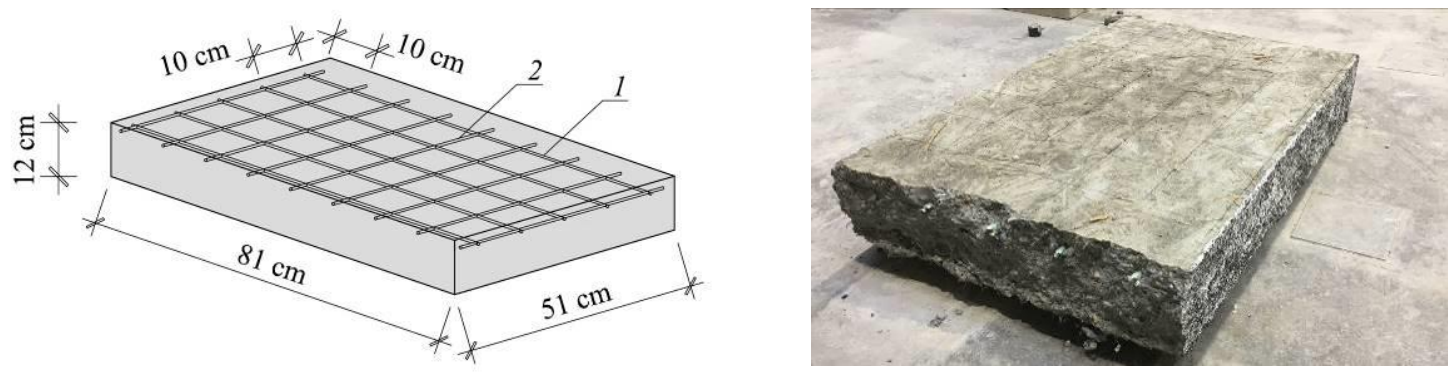

Figure 1. Specimen of concrete slab reinforced with non-metallic mesh: 1 - main wire 2) braided wire

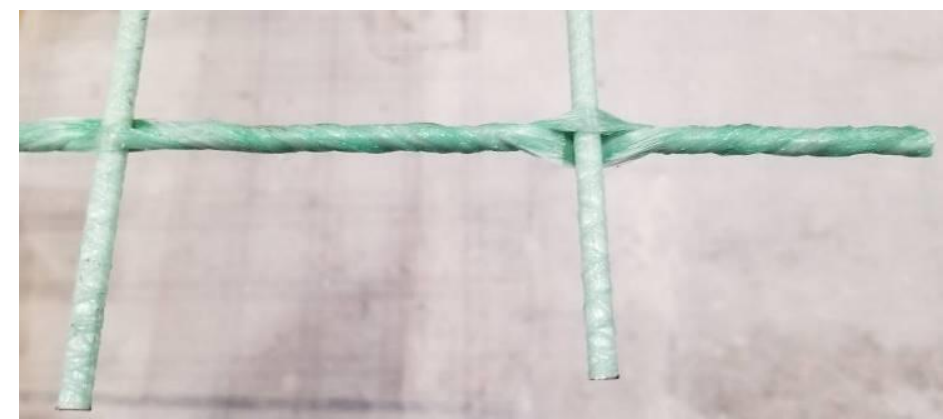

Figure 2. The reinforcement used in the tested slab

For localising the reinforcement, two masonry specimens were prepared. Each of them was composed of four masonry units made of AAC, with the strength $f_{b}=4.04 \mathrm{~N} / \mathrm{mm}^{2}$ and nominal density of $600 \mathrm{~kg} / \mathrm{m}^{3}$ placed on thin-layer mortar of class M5. Test results for masonry units of the mortar and the masonry itself are described in papers $[5,26]$. The width of the model was equal to the width of a single mortar unit, the height was $970 \mathrm{~mm}$, and the thickness was $180 \mathrm{~mm}$. Different types of reinforcement (Fig. 3) were laid in individual joints in both models. There were used two metallic meshes, two meshes from fibre glass, and two meshes from basalt fibre.

A steel mesh with wires having a diameter of $1.2 \mathrm{~mm}$ and mesh size of $12 \times 12 \mathrm{~mm}$ (Fig. 4a) was laid in the upper joint in the first model. The mesh wires were protected against corrosion by hot dip 
galvanisation. In the central joint, there was a fibreglass mesh with a protective latex cover (size $10 \times 12 \mathrm{~mm}$ ). A weft section was $0.42 \times 2 \mathrm{~mm}$, and a warp was composed of three fibres with the smallest section of $2 \times 0.2 \times 0.4 \mathrm{~mm}$ (Fig. $4 \mathrm{~b}$ ). The mesh density was $2500 \mathrm{~kg} / \mathrm{m}^{3}$ In the bottom joint, there was a basalt mesh (size $30 \times 30 \mathrm{~mm}$ ). A weft section was $0.8 \times 3.2 \mathrm{~mm}$, and a warp was composed of four fibres with the smallest section of $0.3 \times 0.9 \mathrm{~mm}$ (Fig. 4c). The mesh density was $1800 \mathrm{~kg} / \mathrm{m}^{3}$.
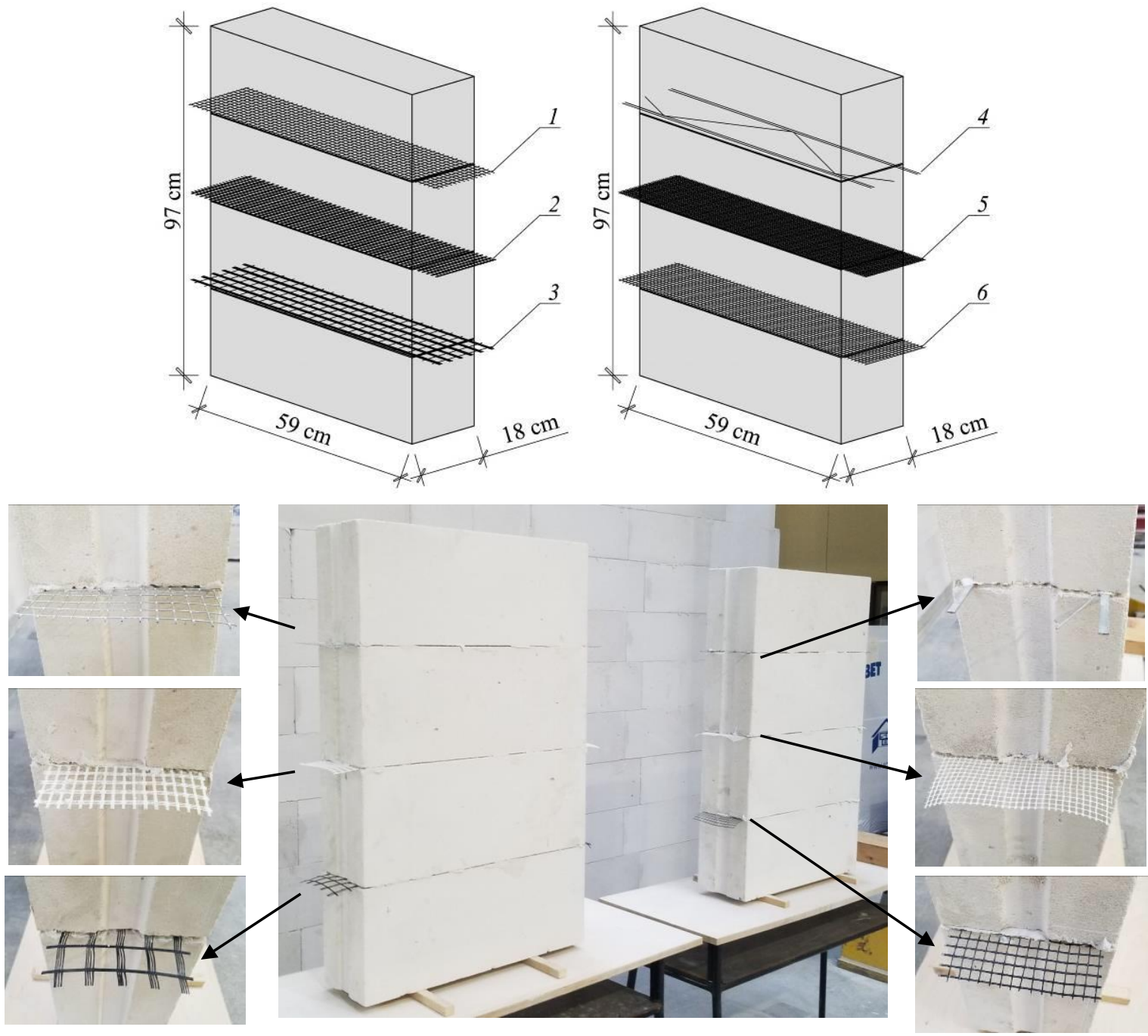

Figure 3. Masonry specimens used for tests: 1 - steel reinforcement mesh (size $12 \times 12 \mathrm{~mm}$ ), 2 - fibreglass reinforcement mesh (size 10x12 mm), 3 - basalt reinforcement mesh (size 30x30 mm), 4 - truss-type reinforcement, 5 - fibreglass reinforcement mesh (size $5 \times 5 \mathrm{~mm}$ ), 6 - basalt reinforcement mesh (size $8 \times 8 \mathrm{~mm}$ )

The upper joint in the second model had a truss-type reinforcement intended for masonry walls built on thin joints. This reinforcement was composed of two flat bars with a section of $1.6 \times 8 \mathrm{~mm}$ and trussing from a wire having a diameter of $1.6 \mathrm{~mm}$ (Fig. 4d). The spacing of flat bars was $140 \mathrm{~mm}$, and the reinforcement was protected against corrosion by hot dip galvanisation. In the central joint, there was a mesh from fibreglass (size $5 \times 5 \mathrm{~mm}$ ). A weft section was $0.22 \times 1.5 \mathrm{~mm}$, and a warp was composed of two fibres with the smallest diameter of $0.3 \mathrm{~mm}$ (Fig. 4e). The mesh density was 2550 $\mathrm{kg} / \mathrm{m}^{3}$ Basalt mesh (size of $8 \times 8 \mathrm{~mm}$ ) was laid in the bottom joint in the second model. The mesh had a weft section of $0.5 \times 1.5 \mathrm{~mm}$, and a warp with the smallest cross-section of $2 \times 0.3 \times 0.6 \mathrm{~mm}$ (Fig. $4 \mathrm{f})$. The basalt mesh density was $1800 \mathrm{~kg} / \mathrm{m}^{3}$. 
a)

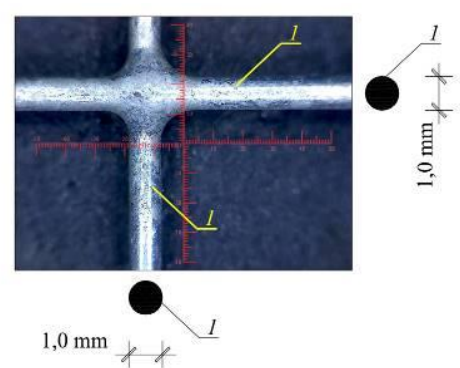

d)

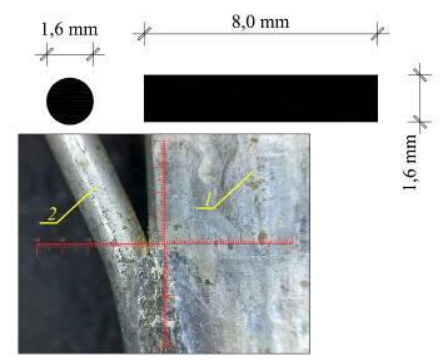

b)

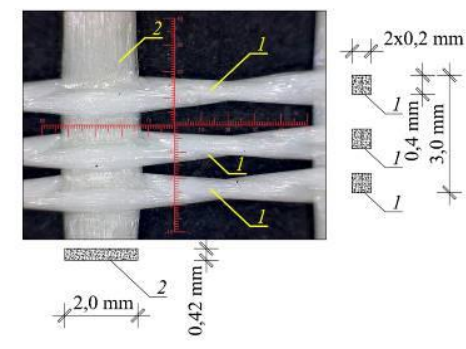

e)

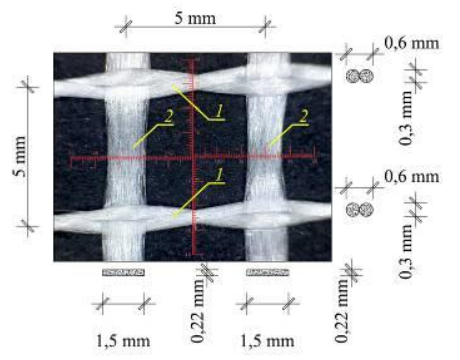

c)

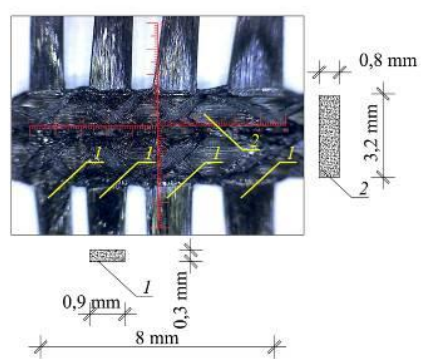

f)

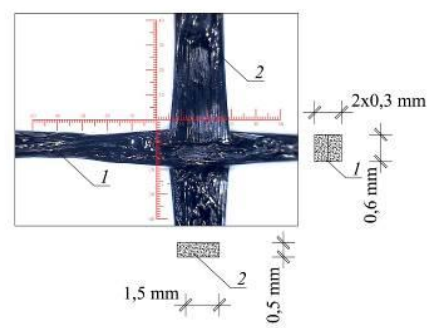

Figure 4. A microscopic view of reinforcement used for tests: (a) steel reinforcement mesh with a diameter of $1.2 \mathrm{~mm}$, (b) - fibreglass mesh (size 10x12 mm), (c) basalt fibre mesh (size 30x30 mm),

(d) truss-type reinforcement, (e) fibreglass mesh (size $5 \times 5 \mathrm{~mm}),(\mathbf{f})$ basalt fibre mesh (size 8x8 mm)

\section{Measurement techniques and equipment}

The ultrasonic tomograph and GPR device were used for tests, with an additional application of the electromagnetic scanner for masonry models. The applied equipment is shown in Fig. 5. The ultrasonic tomograph was equipped with eight measuring transducers in each three rows, operating within the frequency range of $15 \div 100 \mathrm{kHz}$. Each measuring transducer was emitting an ultrasonic sound and echoes were received by other transducers. Individual transducers were sending their own sounds one after another with a delay of $8 \div 200 \mathrm{~ms}$. A completed measurement in one row included 28 scans (Fig. 6).

Radar measurements employed the GPR system with antennae generating the measurement signal with progressively varying frequency within the range of $0.2 \div 4.0 \mathrm{GHz}$. The upper limit of obtained frequencies was particularly important for tested elements. The maximum thickness of elements tested with that device was $70 \mathrm{~cm}$. This device involves time of flight method (TOFM), which simultaneously records the received signal and the movement of wheels in the measuring transducer.

An electromagnetic scanner was the last equipment used while testing masonry units. The scanning head was equipped with a circumferential transmitting coil and seven receiving coils. The analysis was conducted for current induced in receiving coils. This equipment could only detect metallic reinforcement built into top joints in masonry models.

A measuring grid, with a mesh size $10 \times 10 \mathrm{~cm}$, shown in Fig. 7, was plotted onto planes of all models. In case of tests using ultrasound tomography, a linear scan was taken which ran through the whole height of the measuring base beginning at the top of the model. In case of the GPR equipment and electromagnetic scanner, tests were conducted on the whole marked surface. Additionally, linear scans of masonry specimens were made using the GPR equipment along the height of the measuring base. Linear scans began at the base bottom (in accordance with the measuring tool requirements). 


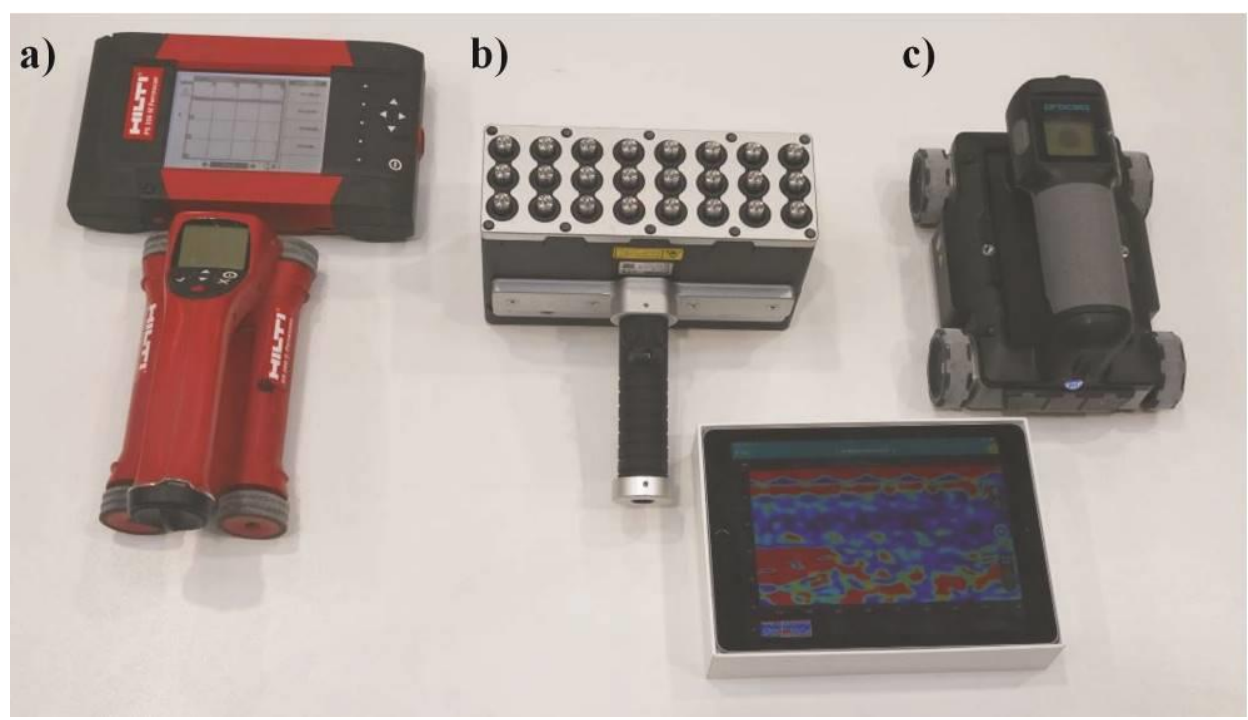

Figure 5. Applied measuring equipment, (a) electromagnetic scanner, (b) ultrasonic tomograph, (c) radar scanner

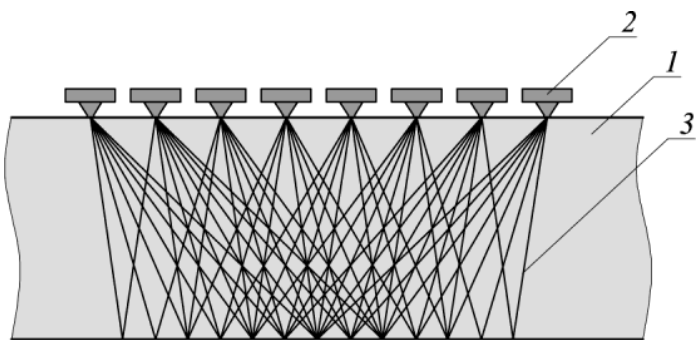

Figure 6. Principles of measurements made with ultrasonic tomograph 1 - tested element, 2 ultrasonic transducer, 3 - ultrasound beam

a)

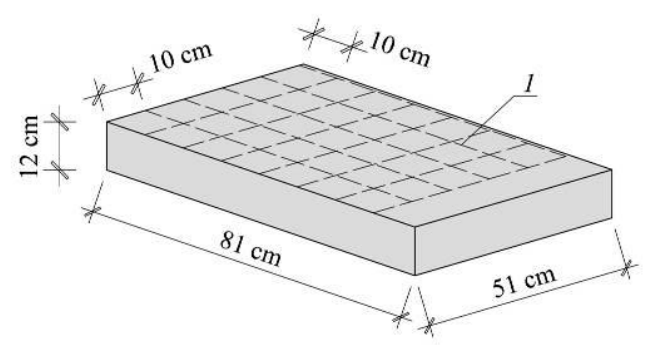

b)

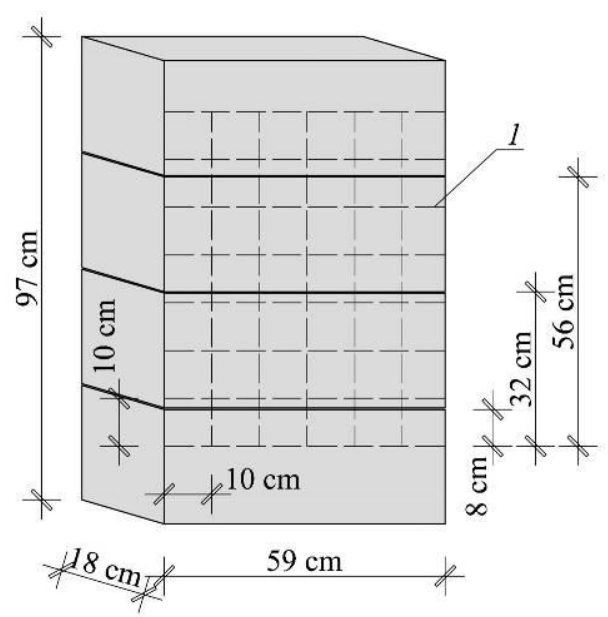

Figure 7. Measuring bases plotted onto elements, (a) reinforced concrete slab, (b) masonry models, 1 - measuring grid

\section{Test results}

Fig. 8 illustrates the result of a linear scan taken with an ultrasonic tomograph, marking location of reinforcement in the model. We have succeeded in obtaining the reinforcement image, also it is not so clearly visible as in case of metallic reinforcement. Figure 9 shows the surface scan taken with the GPR equipment. It is a clear image of the non-metallic reinforcement, and some disturbance visible above the central part of the scan (a red spot) is the result of using a steel slab with a hook for transporting an element. 


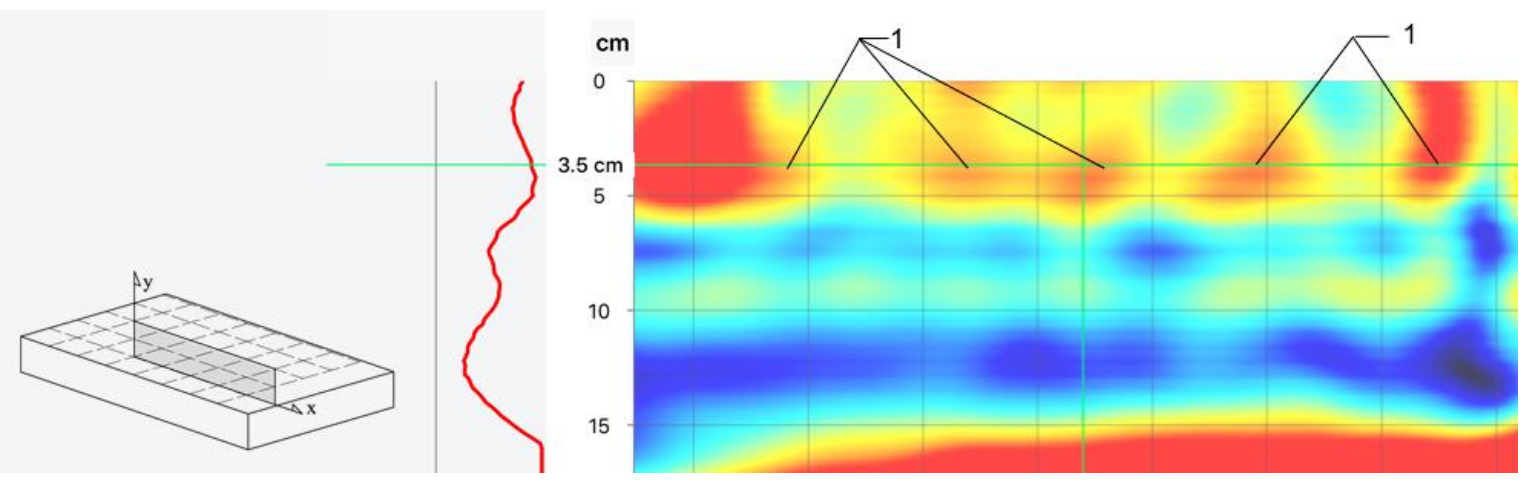

Figure 8. Section of the tested slab obtained from the ultrasonic scanner (a linear scan) 1 - non-metallic reinforcement, 1 - localised reinforcement

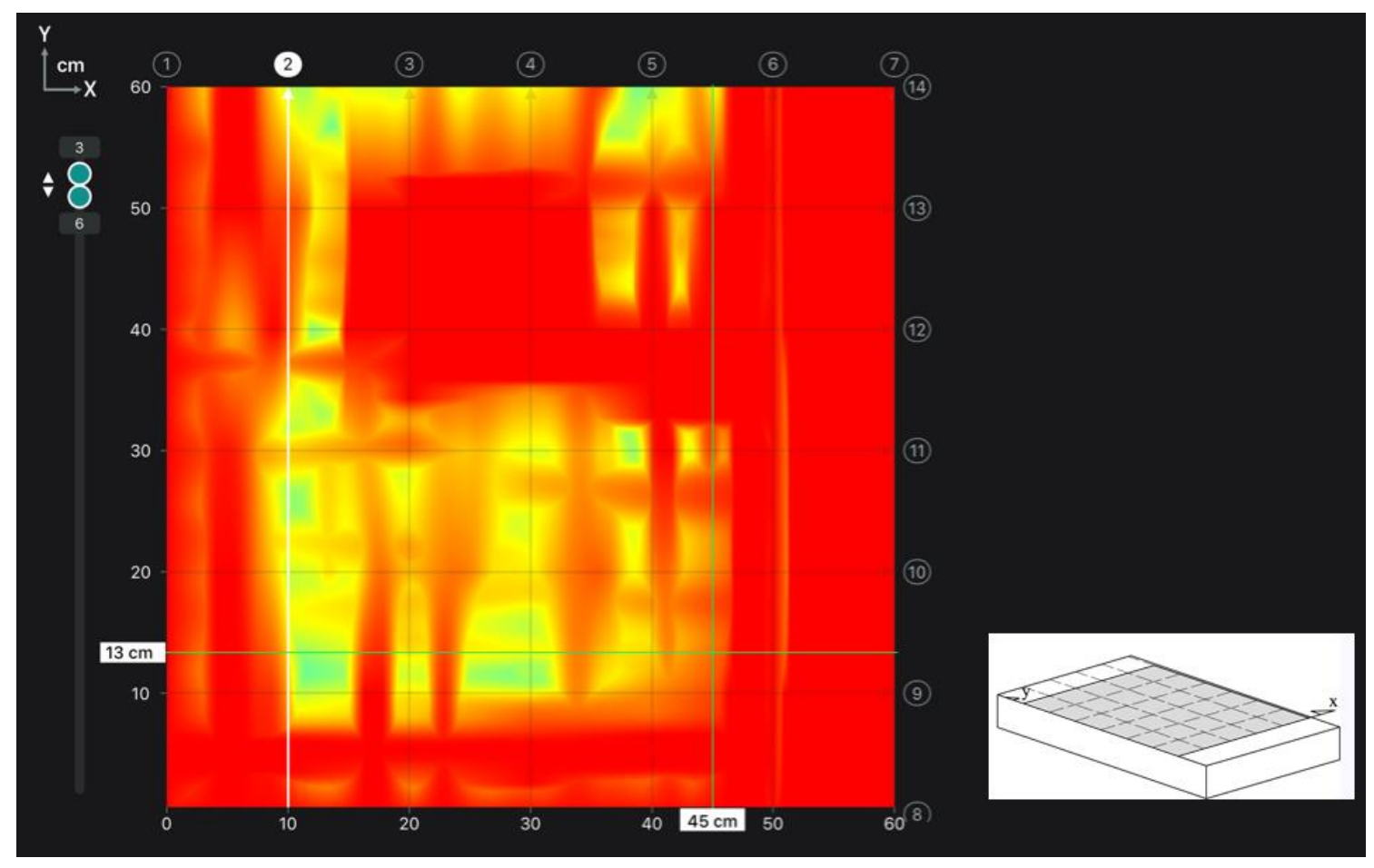

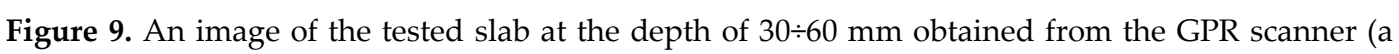
surface scan)

The reinforcement in the slab has a considerably large diameter, and is laid in parallel to the scanned surface, and its density significantly differs from concrete. The reinforcement with smaller diameters, higher density and perpendicular to the tested surface is much more difficult to be detected. However, an attempt was made to detect such reinforcement in masonry specimens. Fig. 10a presents a linear measurement made with the ultrasonic tomograph, and Fig. 10b shows a similar result from the linear measurement with the GPR equipment. Both figures show the marked location of the tested reinforcement. However, the result from the GPR equipment is the mirror reflection to show a better comparison with the result obtained from the ultrasound measurement (the scan was taken in a reverse direction). The slight reinforcement from fibreglass mesh (section 2 shown in scans) was not detected in both cases. But both devices detect the metallic mesh much better despite its very small diameter. The first wire of the metallic mesh is clearly visible in the GPR scan (a hyperbole illustrating location of the mesh wire is in Fig. 10b). More distant wires are not visible because their diameter is very small. Some anomalies of the metallic mesh can be also visible in the ultrasound scan. The basalt mesh (section 3 shown in scans) is barely visible in both scans. Some scan disorders are observed, but the measurement interpretation is generally impossible without knowing the model content. 
a)

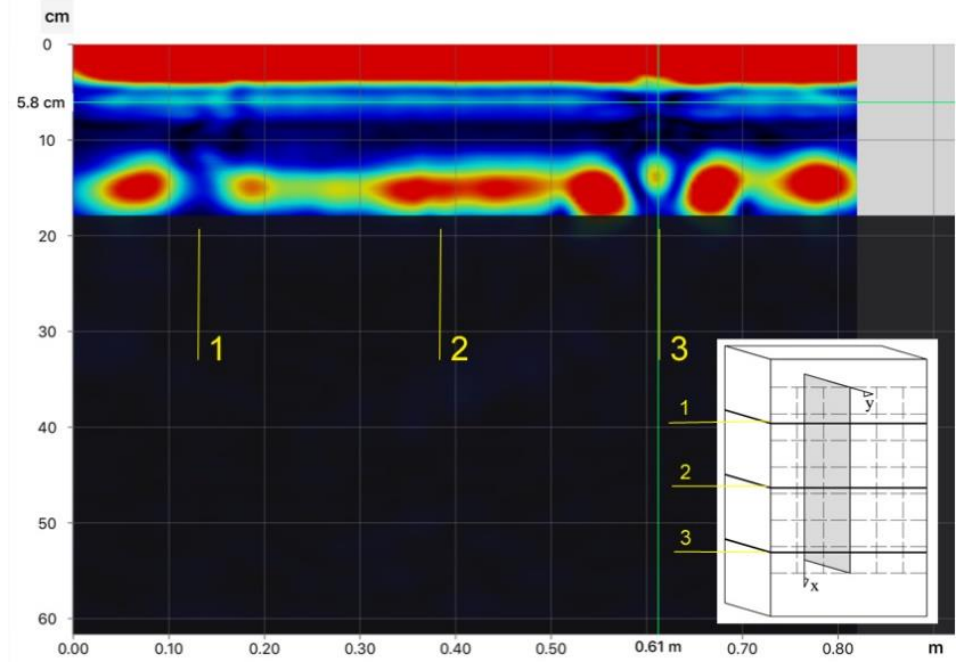

b)

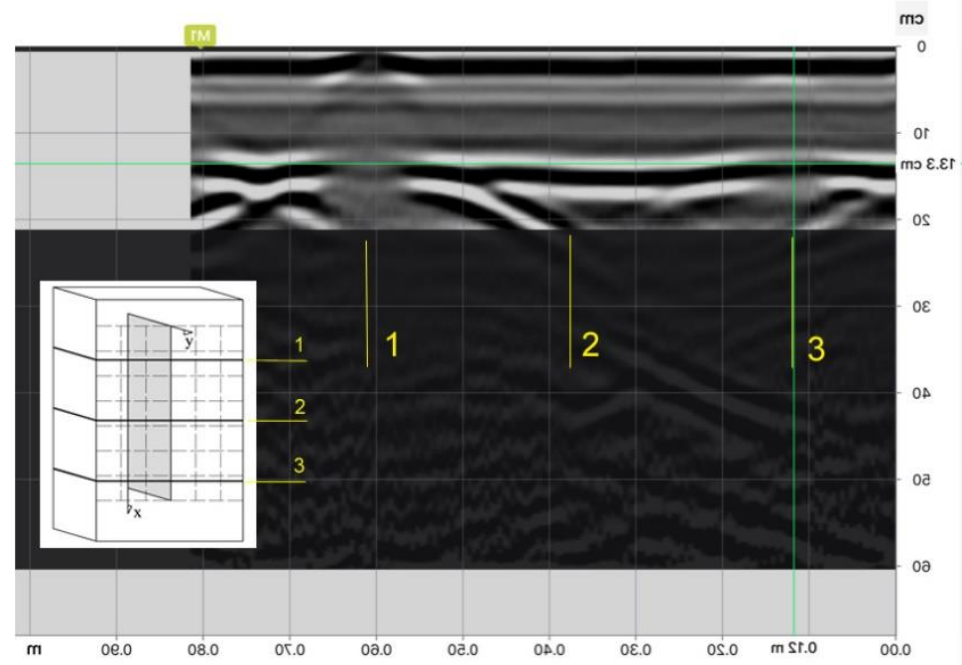

Figure 10. Linear scans (sectional view of the element) from tests performed with, (a) ultrasonic tomograph, (b) GPR scanner, 1- location of steel mesh with a diameter of $1.2 \mathrm{~mm}, 2$ - location of fibreglass mesh (size 10x12 mm), 3 - location of basalt mesh (size 30x30 mm),

Figure 11 shows the result form the surface scan taken with the GPR equipment Like in Fig. 10, there is a marked location of the reinforcement. Like in the linear scan, metal reinforcing mesh and basalt reinforcing mesh were localised, but basalt reinforcing mesh was the most visible.

Similar tests were performed on the second masonry model. Fig. 12a presents a linear measurement made with the ultrasonic tomograph, and Fig. 12b shows a similar result from the linear measurement with the GPR equipment. Like in the model 1, the slight reinforcement from the fibreglass mesh (section 2 shown in scans) was not detected by any of both techniques. These instruments are more effective in detecting the truss-type reinforcement. The first wire (the upper one in the scan) of the metal truss is clearly seen in case of both tests. The basalt mesh (section 3 shown in scans) is barely visible in both scans, like in the model 1 . The interpretation of measurements is also impossible without knowing the model content.

Figure 13 shows the surface scan taken with the GPR equipment, on which the reinforcement location was marked. Like in the linear scan, metal reinforcing mesh and basalt reinforcing mesh were localised, but basalt reinforcing mesh was the most visible.

Electromagnetic tests were only conducted for visualisation because it is commonly known that this method is not used for detecting the non-metallic reinforcement. However, the authors were considering whether the mesh with small diameter wires, built into the model No. 1, was likely to be detected. And tests resulted in the image of the metallic reinforcement in both models (Fig. 14). 


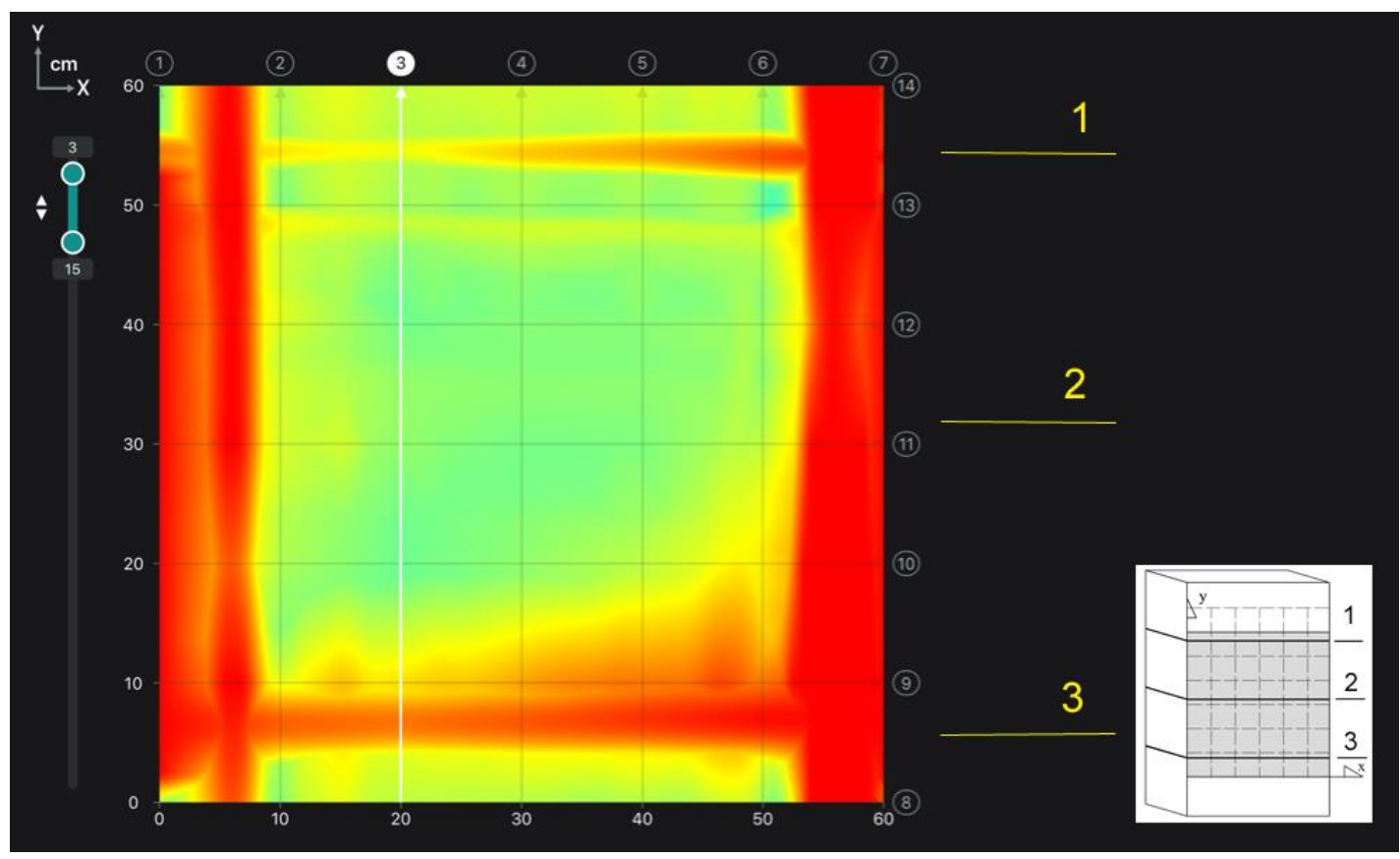

Figure 11. An image of the tested slab at the depth of $30 \div 150 \mathrm{~mm}$ obtained from the GPR scanner (a surface scan)

a)

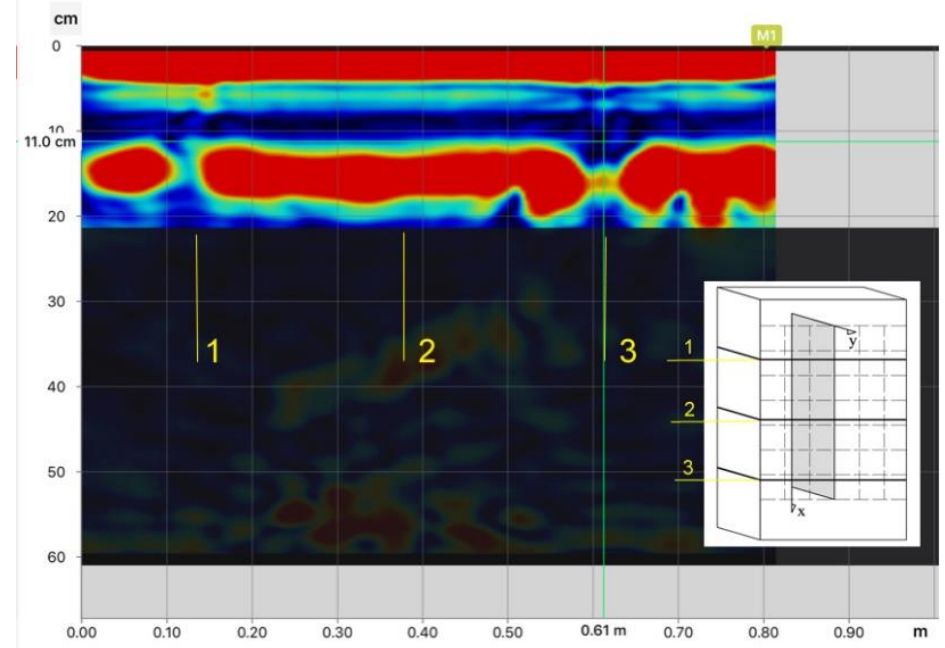

b)

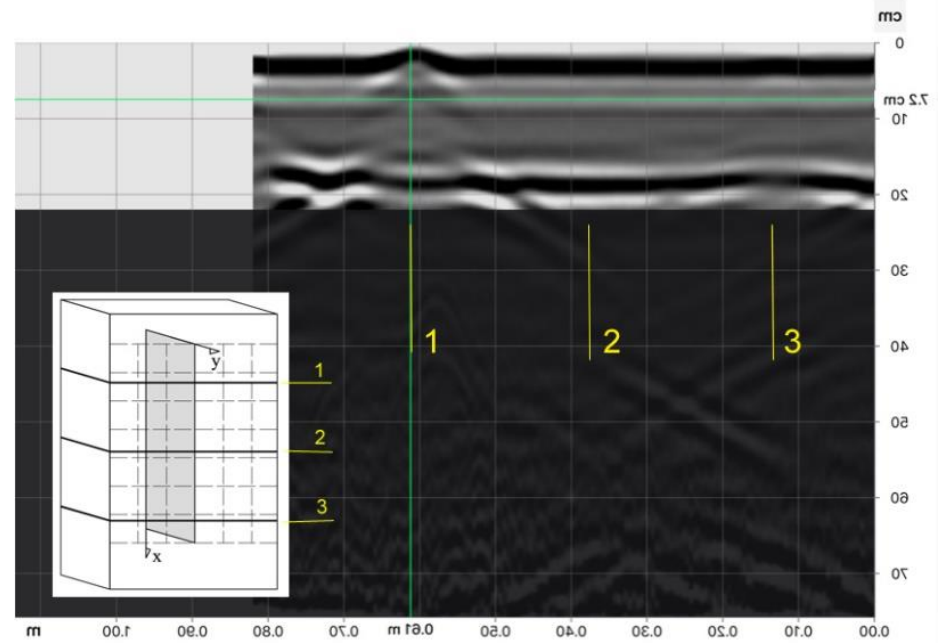

Figure 12. Linear scans (sectional view of the element) from tests performed with, (a) ultrasonic tomograph, (b) GPR scanner, 1- location of truss-type reinforcement, 2 - location of fibreglass mesh (size $5 \times 5 \mathrm{~mm}$ ), 3 - location of basalt mesh (size $8 \times 8 \mathrm{~mm}$ ), 


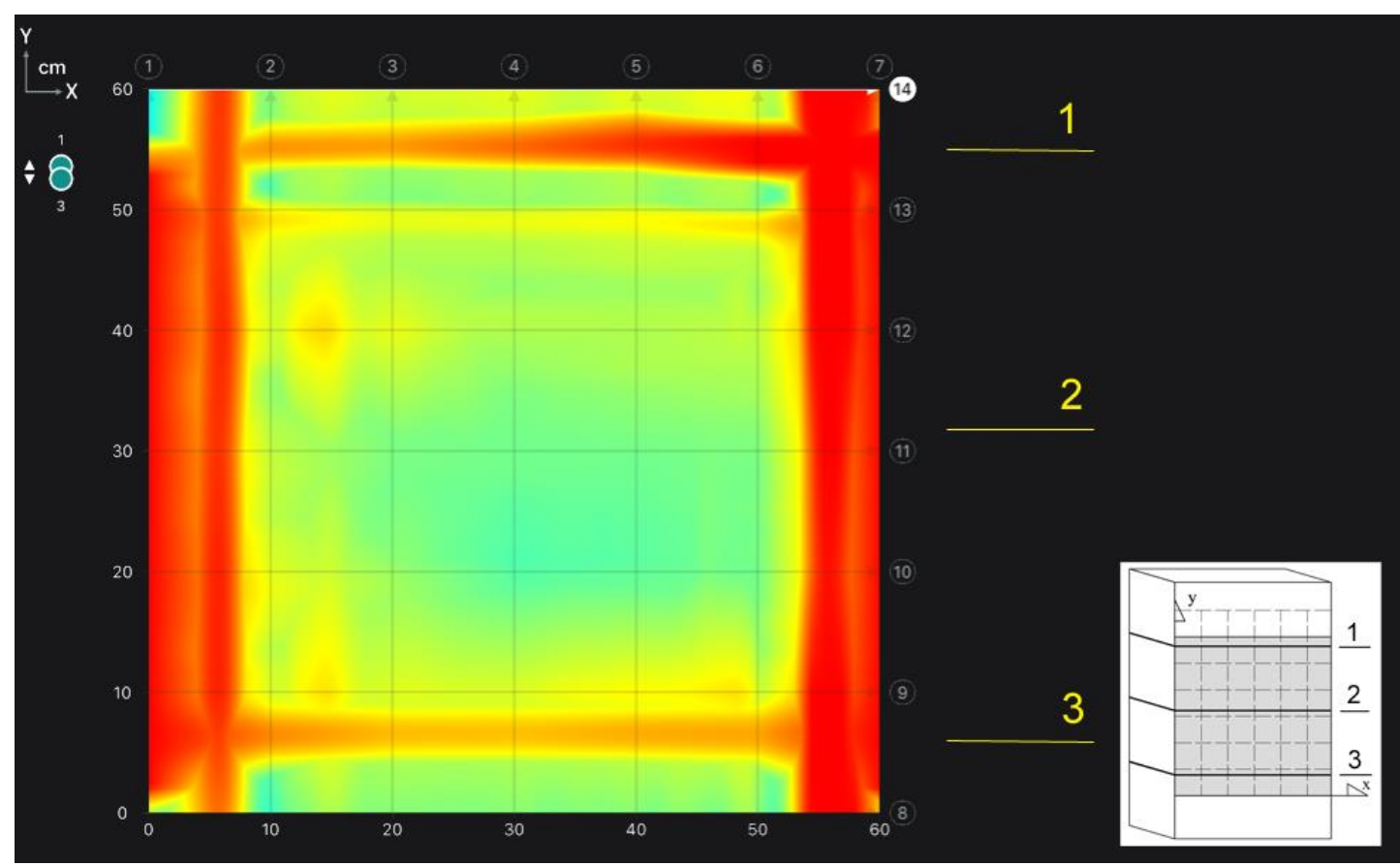

Figure 13. An image of the tested slab at the depth of $10 \div 30 \mathrm{~mm}$ obtained from the GPR scanner (a surface scan)

a)

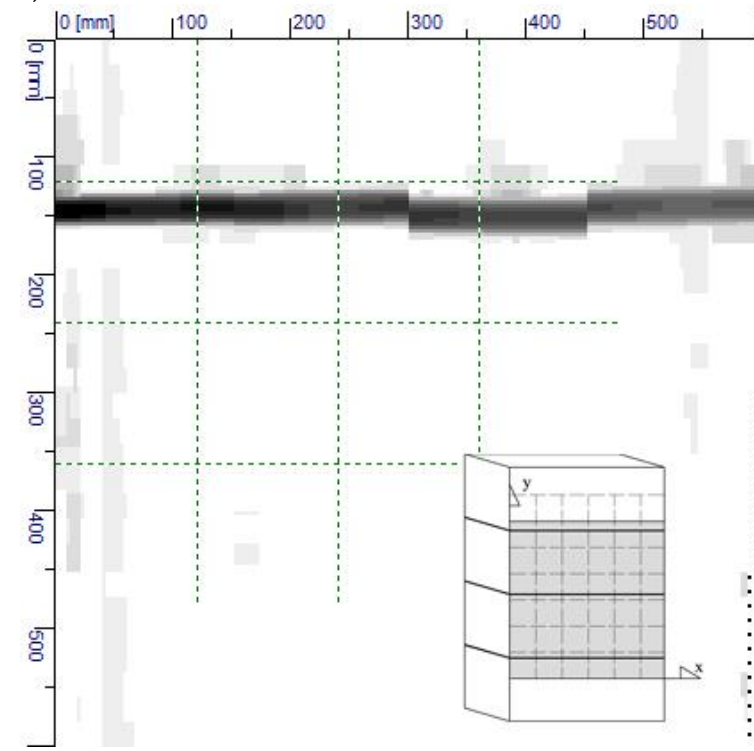

b)

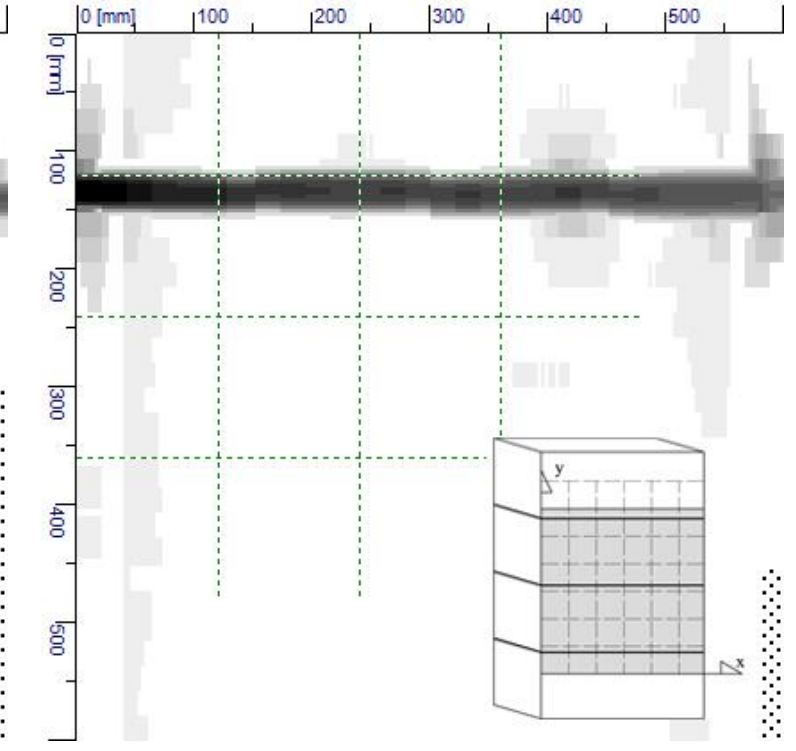

Figure 14. Results from electromagnetic tests, (a) masonry specimen No. 1, (b) masonry specimen No. 2

\section{Conclusions}

The performed tests confirmed difficulties in detecting the non-metallic reinforcement in the structure. Fibreglass meshes with a small diameter (up to $2.0 \mathrm{~mm}$ ) perpendicular to the scanning direction, were not detected. However, fibreglass meshes with a diameter of $5.1 \mathrm{~mm}$, perpendicular to the scanning direction, were detected. The precise detection of basalt meshes was only possible using the radar method.

The employed equipment confirmed its limited usefulness for non-destructive tests aimed at detecting the non-metallic reinforcement. Despite the current technological advancement, results are still burdened with significant uncertainty in terms of interpreting the obtained results. 
For the ultrasonic method, the used commercial equipment should have many measuring transducers on the smallest possible space arranged in a matrix way. The mutual delay in measurements of individual transducers should be as long as possible. For GPR scanners, the equipment with varying frequency of electromagnetic impulse and high values of the limiting frequency should be selected.

Acknowledgements: The authors would like to express particular thanks to Solbet Sp. z o.o., Nova Company and Astra Poland company for supply of materials used during the research works. We would also like to thank Proceq and Viateco for providing research equipment.

\section{References}

1. Nanni, A.; De Luca, A.; Zadeh, H.J. Reinforced Concrete with FRP Bars: Mechanics and Design. CRC Press, 2014.

2. Bank, L.C. Composites for Construction: Structural design with FRP materials. John Willey and Sons LTD, 2006.

3. Kaszubska, M.; Kotynia, R.; Barros, J. Influence of longitudinal GFRP reinforcement ratio on shear capacity of concrete beams without stirrups. Procedia engineering 2017, 193, pp. 361-368.

4. Lau, D.; Pam, H.J. Experimental study of hybrid FRP reinforced concrete beams. Engineering Structures 2010, 32, pp. 3857-3865.

5. Drobiec, Ł. Limitation of cracking in AAC masonry under the window zone. Mauerwerk 2017, 21, pp. 332-342.

6. Drobiec, $€$. The effect of different strengthening systems on the cracking of spandrel walls made of calcium silicate units. Brick and Block Masonry - Trends, Innovations and Challenges. Taylor \& Francis Group, London 2016, pp. 2055-2062.

7. Drobiec, Ł. Tests of AAC walls subjected to vertical loads - Part 1. Zone at the opening. Ce/Pepers 2018, 2, pp. 319-328.

8. Drobiec, Ł. Tests of AAC walls subjected to vertical loads - Part 2. Connection zone of perpendicular walls. Ce/Pepers 2018, 2, pp. 329-337.

9. Jasiński, R.; Drobiec, Ł. Study of Autoclaved Aerated Concrete Masonry Walls with Horizontal Reinforcement under Compression and Shear. Procedia Engineering 2016, 161, pp. 918-924.

10. Jasiński, R. Comparisons of confined and different types of reinforcement on the behavior of masonry shear walls. Ce/Pepers 2018, 2, pp. 353-365.

11. Malhorta V.M., Carino N.J., Handbook on nondestructive testing of concrete, Second edition. CRC Press LCC, ASTM International, Boca Raton, London, New York, Washington D.C. 2004.

12. Bungey J.H., Millard S.G., Grantham M.G., Testing of concrete in structures, $4^{\text {th }}$ edition, Taylor \& Francis, London and New York 2006.

13. Hoła, J.; Schabowicz, K. State-of-the-art non-destructive methods for diagnostic testing of building structures-anticipated development trends. Archives of Civil and Mechanical Engineering 2010, 10, pp. 5-18.

14. Drobiec Ł., Jasiński R., Piekarczyk A. Diagnostic testing of reinforced concrete structures. Methodology, field tests, laboratory tests of concrete and steel. Wydawnictwo Naukowe PWN, Warszawa 2013. (in-Polish).

15. Gholizadeh, S. A review of non-destructive testing methods of composite materials. Procedia Structural Integrity 2016, 1, pp. 050-057.

16. Schabowicz, K.; Sterniuk, A.; Kwiecińska, A. Ultrasonic examination of concrete with one side access in practice. Materials Science and Engineering 2018, 365.

17. Schabowicz, K. Modern acoustic techniques for testing concrete structures accessible from one side only. Archives of Civil and Mechanical Engineering 2015, 15, pp. 1149-1159.

18. Samokrutov, A.A.; Kozlov, V.N.; Shevaldykin, V.G. Ultrasonic testing of concrete objects using dry acoustic contact. Methods, instruments and possibilities. The 5th International Conference ",non-Destructive Testing and Technical Diagnostics in Industry". Mashinostroenie, 2006, p.152.

19. Keo, S.A.; Brachelet, F.; Breaban, F.; Defer, D.; Steel Detection in Reinforced Concrete Wall by Microwave Infrared Thermography. NDTEE International 2014, 62, pp. 172-177.

20. Swiderski, W. Non-Destructive Testing of Carbon Fiber Reinforced Plastic by Infrared Thermography Methods. International Scholarly and Scientific Research \& Innovation 2016, 10, pp. 1470-1473.

21. Bungey, J.H. Sub-surface radar testing of concrete: a review. Construction and Building Materials 2004, 18, pp. 1-8. 
22. Lachowicz, J.; Rucka, M. 3-D finite-difference time-domain modelling of ground penetrating radar for identification of rebars in complex reinforced concrete structures. Archives of Civil and Mechanical Engineering 2018, 18, pp. 1228 - 1240.

23. Lachowicz, J.; Rucka, M. Application of GPR method in diagnostics of reinforced concrete structures. Diagnostyka 2015, 16.

24. Rucka, M.; Lachowicz, J., Zieleńska M. GPR investigation of the strengthening system of a historic masonry tower. Journal of Applied Geophysics 2016, 131, pp. 94-102

25. Agred, K; Klysz, G.; Balayssac, J.P. Location of reinforcement and moisture assessment in reinforced concrete with a double receiver GPR antenna. Construction and Building Materials 2018, 188, pp. 1119-1127.

26. Drobiec, Ł.; Jasiński, R.; Rybarczyk, T. The influence of the type of mortar on the compressive behaviour of walls made of Autoclaved Aerated Concrete (AAC). Brick and Block Masonry - Trends, Innovations and Challenges. Taylor \& Francis Group, London 2016, pp. 1531-1538. 